\title{
Genotypic Characterization of Aminoglycoside Resistance Genes from Bacteria Isolates in Selected Municipal Drinking Water Distribution Sources in Southwestern Nigeria
}

\author{
Adesoji. A. Timilehin ${ }^{1 *}$, Olatoye. I. Olufemi2,3, Ogunjobi. A. Adeniyi ${ }^{4}$
}

\section{OPEN ACCESS}

Citation: Adesoji. A. Timilehin, Olatoye I. Olufemi, Ogunjobi. A. Adeniyi. Genotypic Characterization of Aminoglycoside Resistance Genes from Bacteria Isolates in Selected Municipal Drinking Water Distribution Sources in Southwestern Nigeria. Ethiop J Health Sci. 2019; 29(3): 321 .

doi:http://dx.doi.org/10.4314/ ejhs.v29i3.4 Received: August 29, 2018

Accepted: December 21, 2018

Published: May 1, 2019

Copyright: (C) 2019 Adesoji A. T. et al. This is an open access article distributed under the terms of the Creative Commons

Attribution License, which permits unrestricted use, distribution, and reproduction in any medium, provided the original author and source are credited.

Funding: Partial funding from Paul G. Allen School for Global Animal Health, Washington State University, USA

Competing Interests: The authors declare that this manuscript was approved by all authors in its form and that no competing interest exists.

Affiliation and Correspondence:

${ }^{1}$ Department of Microbiology, Federal

University Dutsin-Ma, Katsina State,

Nigeria

${ }^{2}$ Department of Veterinary Public

Health and Preventive Medicine,

University of Ibadan, Oyo State,

Nigeria

${ }^{3}$ Paul G. Allen School for Global

Animal Health, Washington State

University, Washington State, USA and

${ }^{4}$ Department of Microbiology,

University of Ibadan, Oyo State,

Nigeria

*Email: timmyayus2002@yahoo.com

\section{ABSTRACT}

BACKGROUND: Multi-drug Resistant (MDR) bacteria could lead to treatment failure of infectious diseases and could be transferred by non-potable water. Few studies have investigated occurrence of Antibiotic Resistance Genes (ARGs) among bacteria including Aminoglycoside Modifying Genes (AMGs) from Drinking Water Distribution Systems (DWDS) in Nigeria. Here, we aimed at characterization of AMGs from DWDS from selected states in southwestern Nigeria.

METHODS: One hundred and eighty one (181) MDR bacteria that had been previously characterized using $16 S$ rDNA and showed resistance to at least one aminoglycoside antibiotic were selected from treated and untreated six water distribution systems in southwestern Nigeria. MDR bacteria were PCR genotyped for three AMGs:aph (3"') ${ }^{c}$, ant $\left(3^{\prime \prime}\right)^{b}$ and aph(6)-1d .

RESULTS: Out of 181 MDR bacteria genotyped, 69(38.12\%) tested positive for at least one of the genotyped AMGs. Highest (50, $27.62 \%)$ detected gene was ant $\left(3^{\prime \prime}\right)^{c}$ followed by aph $\left(3^{\prime \prime}\right)^{c}(33$, 18.23\%). Combination of aph $\left(3^{\prime \prime}\right)^{c}$ and ant $\left(3^{\prime \prime}\right)^{b}$ in a single bacteria was observed as the highest $(14,7.73 \%)$ among the detected gene combination. Alcaligenes sp showed the highest (10/20) occurrence of ant $\left(3^{\prime \prime}\right)^{b}$ while aph $\left(3^{\prime \prime}\right)^{c}$ was the highest detected among Proteus sp (11/22). Other bacteria that showed the presence of AMGs include: Acinetobacter, Aeromonas, Bordetella, Brevundimonas, Chromobacterium, Klebsiella, Leucobacter, Morganella, Pantoae, Proteus, Providencia, Psychrobacter and Serratia.

CONCLUSIONS: High occurrence of ant (3") ${ }^{c}$ and aph (3") among these bacteria call for urgent attention among public health workers, because these genes can be easily disseminated to consumers of these water samples if present on mobile genetic elements like plasmids, integrons and transposons.

KEYWORDS: Aminoglycoside-modifying gene, antibiotic resistance, treated water and untreated water 


\section{INTRODUCTION}

Aminoglycosides (Amgs) are potent, broadspectrum antibiotics with many desirable properties for the treatment of human infections (1). This class of antibiotics exert their antibacterial activity by inhibiting the protein synthesis via binding to the $16 \mathrm{~S}$ rRNA and by disrupting the bacterial cell membrane integrity (2). Over the years, the emergence of resistant strains has reduced the potential of aminoglycoside in empiric therapies (3).

Safe potable water is essential for people and animals. Safe drinking water is, however, required to be devoid of fecal coliform bacteria, thereby, reducing the risk of waterborne diseases. In developing countries, poor water quality from untreated or ineffective and inefficient water treatment contribute to the risk of child mortalities resulting from waterborne infectious diarrhea (4). The most common and widespread health risks associated with drinking water in developing countries are of biological origin (5). Municipal water distribution systems have been found to support growth of certain antibiotic resistant bacteria populations and it is also an important reservoir for the spread of antibiotic resistance to opportunistic pathogens (6). It is well documented that horizontal gene transfer is a key route to the acquisition of aminoglycoside resistance genes (7). The genes that encode the modifying enzymes can reside on the chromosome or on mobile genetic elements such as plasmids and transposons (8) which are readily transferable from bacteria of similar species and even between different bacterial species (9).

A number of mechanisms of aminoglycoside resistance known includes reduced uptake or decreased cell permeability (10), alteration of the ribosomal binding site by rRNA methylases (11$13)$, overexpression of efflux pump $(14,15)$ and production of aminoglycoside-modifying enzymes (AMEs). However, among resistance mechanisms to aminoglycoside, inactivation by aminoglycosidemodifying enzymes is the most important, both in terms of level and frequency of resistance conferred to the bacterium (1). There are three family of aminoglycoside-modifying enzymes including aminoglycoside acetyltransferases (AACs), phosphotransferases (APHs), and nucleotidyltransferases (ANTs).

In Gram-negative organisms, resistance to aminoglycosides such as amikacin, tobramycin and gentamycin was reported to vary from $32.6 \%$ to $83.6 \%$ which is mediated by AAC (6) and APH (2) activity (16-18). Furthermore, resistance to tobramycin and amikacin is also mediated by an ANT(4) enzyme encoded by ant (4) gene (19). An earlier study from India reported the prevalence of $a a c\left(6^{\prime}\right)-I$ and $a a c$ (3)-II was $42.8 \%$ and $20.4 \%$, respectively (16). Odumosu et al. (20) was the only Nigerian author found to have reported aac (6') and ant (2)-I" among Pseudomonas aeruginosa. Therefore, surveillance study on aminoglycoside resistance due to AMEs is very scanty among Nigerian isolates. However, in combatting the spread of antibiotic resistance, monitoring of phenotypic resistance rates is essential and the availability of information about the epidemiology of the genetic elements responsible for the expressed phenotype is crucial (21). We previously reported the isolation of several opportunistic bacteria like Acinetobacter spp, Aeromonas spp, Brevundimonas spp, Morganella sp, Psychrobacter, Pantoae spp etc that phenotypically exhibited resistance to gentamicin, kanamycin and streptomycin in municipal drinking water distribution systems from south Western Nigeria. Studies on the physicochemical parameters and microbial qualities of these water samples were also conducted (22-24). Therefore, this study aimed at detection of AMEs such as aph (3") $)^{c}$, aph (6)$1 d^{d}$ and ant $(3 \text { "' })^{b}$ from these isolates and determination of plamid profiles.

\section{MATERIALS AND METHODS}

Sample collection, sample sites, bacteria isolates, molecular characterization and antibiotic resistant profiles: Sampling methods, dam description, antibiotics resistant profiles and molecular characterization used in this study were properly elucidated in our previous studies (22-26). However, for readers' clarity, six dams from three southwestern Nigeria states (i.e. two dams per state) that include Osun, Oyo and Ondo State were selected for this study. Thereafter, ninety-six water samples (100 ml per sample) were purposively collected aseptically into sterile screw cap bottles

DOI: http://dx.doi.org/10.4314/ejhs.v29i2.4 
across the Drinking Water Distribution Systems (DWDS) of these dams that make use of Water Treatment Plants (WTPs) for treatment of their raw water. These samples were collected four times between December 2010 and July 2011 from raw, treated and two randomly selected municipal distribution taps of these sampled DWDS. These WTPs employ conventional methodologies for water purification, which include filtration, flocculation, sedimentation and disinfection. These dams include Ife and Ede Erinle dams located in Obafemi Awolowo University, Ile-Ife and Ede respectively in Osun state. Eleyele and Asejire dam sited in Ibadan and Asejire, Oyo State respectively.
Owena-Ondo dam located near Akure town, Ondo State and Owena-Ijesha dam located near Ilesha, Osun State were also included in the study. Maps of these sites are presented on Figure 1. Ife dam is the smallest $\left(0.95 \mathrm{~km}^{2}\right)$ while Ede Erinle Dam extends approximately $14.0 \mathrm{~km}^{2}$ at the normal water level. The Eleyele Dam $\left(1.5 \mathrm{~km}^{2}\right)$ serves the Ibadan metropolis in Oyo State Nigeria. The Asejire Dam $\left(7.5 \mathrm{~km}^{2}\right)$ is located in Asejire, approximately $30 \mathrm{~km}$ east of Ibadan. The OwenaOndo Dam is $7.8 \mathrm{~km}^{2}$ while the Owena-Ijesha Dam is $1.7 \mathrm{~km}^{2}$ and is located near Ilesha, in Osun State.

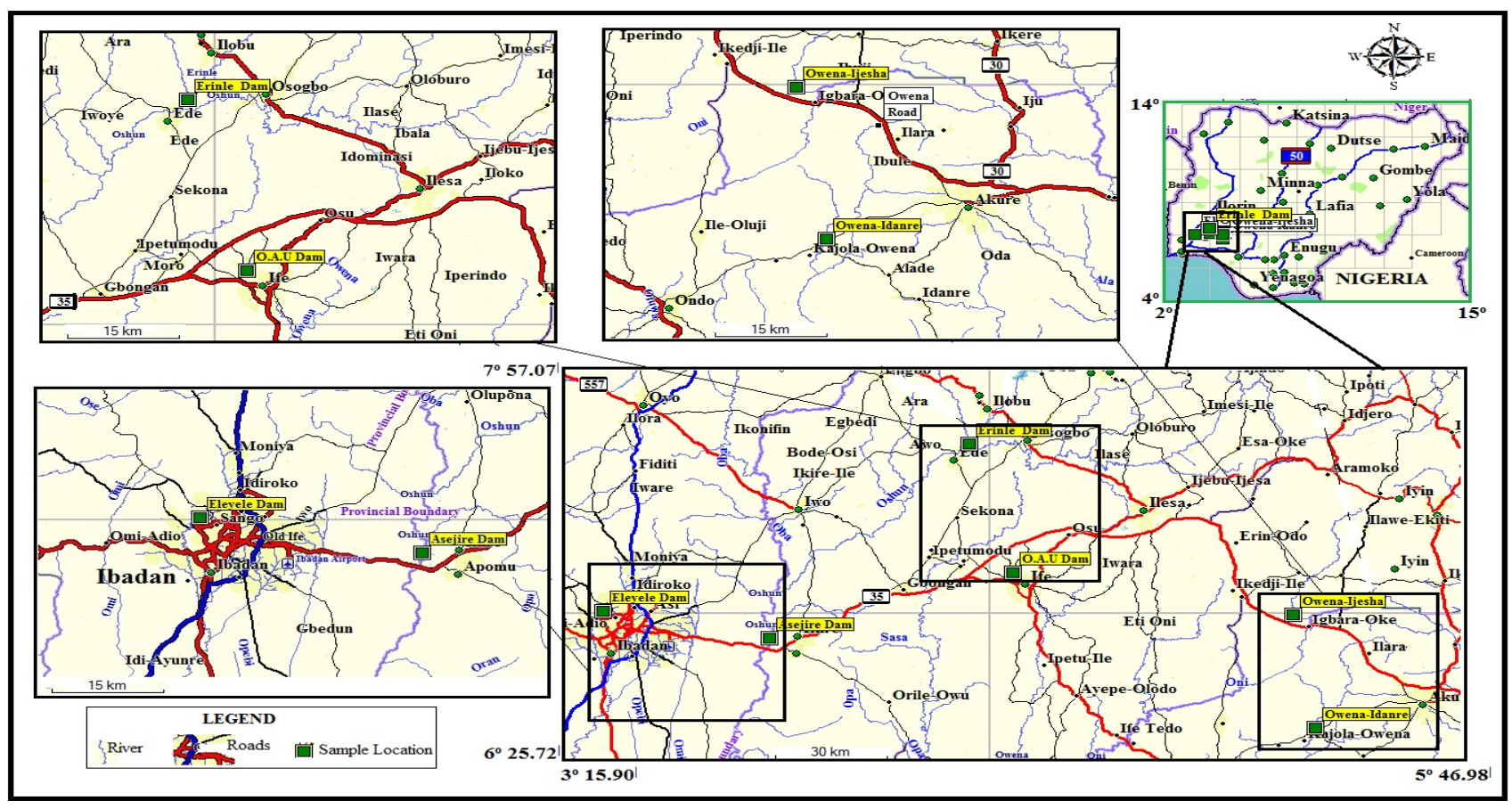

Figure 1: Location of sampled dams, indicated by green squares (The map was created by Dr. Akinola Eluwole)

After samples were collected, they were serially diluted and plated on Nutrient agar, eosin methylene blue agar (EMB), and Deoxycholate agar (DCA). Thereafter, bacteria were picked with the aim of maximizing the diversity of colony morphology represented from each sample. Picked colonies were re-streaked on Nutrient agar to obtain pure cultures. These were subsequently transferred to Nutrient agar slants and also stored in phosphate buffer glycerol at $-80^{\circ} \mathrm{C}$. Molecular characterization of bacteria using $16 \mathrm{~S}$ rDNA sequencing was also determined. Afterwards, antibiotic susceptibility of isolates with various concentration of antibiotics was determined using a point inoculation method as previously described (25). Thereafter, we selected 181 Multi-Drug Resistant (MDR) bacteria for AMEs genotyping based on resistance to over three classes of antibiotics and at least one aminoglycoside antibiotic tested for. The aminoglycoside antibiotics include gentamycin, kanamycin and streptomycin.

DOI: http://dx.doi.org/10.4314/ejhs.v29i2.4 
Genotyping isolates for aminoglycoside resistance genes: The diversity of aminoglycoside resistance genes encoded in the genome of 181 aminoglycoside and multidrug resistant isolates was assessed by testing for the presence of three selected AMEs belonging to the family phosphotransferases $\left(\operatorname{aph}\left(3^{\prime \prime}\right)^{c}\right.$ and $\left.\operatorname{aph}(6)-1 d^{d}\right)$ and adenylases $\left(\operatorname{ant}\left(3^{\prime \prime}\right)^{b}\right)$. Total genomic extraction of isolates was carried out using the Chelex extraction method as previously described $(25,26)$. The PCR amplification reaction include $5 \mu \mathrm{l}$ of the chelex extracted DNA as template, with $2 \mathrm{mM} \mathrm{MgCl}_{2}, 0.8$ $\mathrm{mM}$ dNTPs, $0.2 \mu \mathrm{l}$ of each of the forward and reverse primer and $1 \mathrm{X}$ PCR buffer. Reaction conditions included $1 \mathrm{~min}$ denaturation $\left(95^{\circ} \mathrm{C}\right)$ followed by 30 cycles of $96^{\circ} \mathrm{C}$ for $30 \mathrm{~s}, 55^{\circ} \mathrm{C}$ for $30 \mathrm{~s}$ and $72^{\circ} \mathrm{C}$ for $3 \mathrm{~s}$ and a final extension of $72^{\circ} \mathrm{C}$ for $10 \mathrm{~min}$. However, primer sequences used for the reaction for the AMEs amplifications are shown in Table 1. The PCR products were separated and visualized by gel electrophoresis $(1 \%)$ toconfirm amplification.

Table 1: Primers used in this study for amplification of Extended beta lactamase (ESBL) resistant genes

\begin{tabular}{|c|c|c|c|c|c|}
\hline Primer pair & Target & Sequence $\left(5^{\prime}-3^{\prime}\right)$ & $\begin{array}{c}\text { Annealing } \\
\text { temperature } \\
\left({ }^{\circ} \mathrm{C}\right)\end{array}$ & $\begin{array}{c}\text { Amplicon } \\
\text { size } \\
\text { (bp) }\end{array}$ & Reference \\
\hline $\begin{array}{l}\text { aph }\left(3^{\prime \prime}\right)^{c}-F \\
\text { aph }\left(3^{\prime \prime}\right)^{c}-R\end{array}$ & $\operatorname{aph}\left(3^{\prime \prime}\right)^{\mathrm{c}}$ & $\begin{array}{l}\text { GCTCAAAGGTCGAGGTGTGG } \\
\text { CCAGTTCTCTTCGGCGTTAG }\end{array}$ & $\begin{array}{l}55 \\
55\end{array}$ & $\begin{array}{l}515 \\
515\end{array}$ & {$[31]$} \\
\hline $\begin{array}{l}\text { ant }\left(3^{\prime \prime}\right)^{\mathrm{b}}-\mathrm{F} \\
\operatorname{ant}\left(3^{\prime \prime}\right)^{\mathrm{b}}-\mathrm{F}\end{array}$ & $\operatorname{ant}\left(3^{\prime \prime}\right)^{\mathrm{b}}$ & $\begin{array}{c}\text { CAGCGCAATGACATTCTTGC } \\
\text { GTCGGCAGCGACA(C/T)CCTTCG }\end{array}$ & $\begin{array}{l}55 \\
55\end{array}$ & $\begin{array}{l}295 \\
295\end{array}$ & ", \\
\hline $\begin{array}{l}\operatorname{aph}(6)-1 d^{d}-F \\
\operatorname{aph}(6)-1 d^{d}-R\end{array}$ & $\operatorname{aph}(6)-1 \mathrm{~d}^{\mathrm{d}}$ & $\begin{array}{l}\text { GACTCCTGCAATCGTCAAGG } \\
\text { GCAATGCGTCTAGGATCGAG }\end{array}$ & $\begin{array}{l}55 \\
55 \\
\end{array}$ & $\begin{array}{l}560 \\
560\end{array}$ & ״, \\
\hline
\end{tabular}

Determination of presence of plasmid on bacteria isolates: This was carried out based on the method described in our previous study (26). This involves picking and inoculating a single colony from pure overnight bacteria culture grown on Luria Bertani (LB) agar into LB Broth, thereafter incubating the broth overnight. One hundred and fifty microliter of the culture was later pelleted by centrifugation for 10 minutes at $1000 x g$. The supernatant was removed and re-suspended in $100 \mu 1$ of lysis buffer (3\% SDS, 50mM Tris pH 12.6 with $50 \mathrm{mM}$ Tris adjusted by $1.6 \mathrm{ml} 2 \mathrm{~N} \mathrm{NaOH}$ up to $100 \mathrm{ml}$ final volume). The mixture was incubated at $55^{\circ} \mathrm{C}$ for 1 hour. The resulting plasmid was extracted with $150 \mu 1$ of Phenol: chloroform $(1: 1$, $\mathrm{v} / \mathrm{v}, \mathrm{pH}$ 7.9) and mixed by inversion several times before spinning at highest speed for 10 minutes. Fifty microliter of the supernatant was transferred into a new tube and mixed with $10 \mu 1$ of a loading dye. The mixture containing the plasmid was run on $1 \%$ agarose gel electrophoresis in $1 \mathrm{X}$ TAE buffer for more than 3 hours at a voltage of $8 \mathrm{v} / \mathrm{cm}$.

Statistical analysis: Principal component analysis (PCA) biplot of relationship between the AMGs, and the sample locations was determined based on correlation matrix of association using PAST statistical software. In the PCA biplot, each AMGs is represented by a line, the line direction indicates that the values of the variables increase in that direction. However, the length of the line is related to the rate of increase. Longer lines are more gradual in increment while shorter lines are faster in increment.

\section{RESULTS}

Selected bacteria, AME positive strains and plasmid profiles: Bacteria $(n=181)$ used in this study were selected from our previous study (2224). It should be noted that results of the physicochemical parameters and microbial qualities of these water samples had also been reported in these previous studies (22-24). However, among these bacteria, those that tested positive for at least one AME gene are presented in Table 2. Combination of $\operatorname{aph}\left(3^{\prime \prime}\right)^{\mathrm{c}}$ and $\operatorname{ant}\left(3^{\prime \prime}\right)^{\mathrm{b}}$ in a single bacteria was observed as the highest (14, 7.73\%) among the detected gene combination in a single bacteria (Table 2). Alcaligenes sp showed the

DOI: http://dx.doi.org/10.4314/ejhs.v29i2.4 
highest (10/20) occurrence of $\operatorname{ant}\left(3^{\prime \prime}\right)^{\mathrm{b}}$ while highest occurrence of $\operatorname{aph}\left(3^{\prime \prime}\right)^{\mathrm{c}}$ was detected among Proteus sp (11/22) as shown in Table 2. Out of a total of 181 MDR and aminoglycoside resistant bacteria genotyped $69(38.12 \%)$ tested positive for at least one of the selected AME genes. The highest $(50,27.62 \%)$ detected gene was ant $\left(3{ }^{\prime \prime}\right)^{c}$ followed by $\operatorname{aph}\left(3^{\prime \prime}\right)^{\mathrm{c}}(33, \quad 18.23 \%)$ as shown in supplementary Table 1. Supplementary Table 1 also shows the frequency of distributions of these genes across the sample locations. Moreover, from Ife Dam, 11 isolates were PCR genotyped from the finished water out of which 3 tested positive for AMEs. Principal Component Analysis (PCA) showed that the most important samples collected (eight) were restricted to: Eleyele raw water, Ife raw water, Asejire raw water, Ife finished water,
Owena Ijesha municipal tap I, Ede raw water, Owena Ondo municipal tap water 2 and Owena Ijesha raw water (Figure 2). The highest eigenvalue (5.62) was observed in the first principal component with percentage variance $(70.21 \%)$. This present study revealed that aminoglycoside resistant positive gene sites (AmRG) and ant $(3)^{b}$ genes were correlated to raw water from Ife Dam and raw water from Asejire Dam. Moreover, the genes and gene combinations: aph $\left(3^{\prime \prime}\right)^{c}$, aph(6)$1 d^{d}$, aph $\left(3^{\prime \prime}\right)^{c}+$ ant $\left(3^{\prime \prime}\right)^{b}$, aph (3') + aph $(6)-1 d^{d}$, ant $\left(3^{\prime \prime}\right) b+\operatorname{aph}(6)-1 d^{d}, \quad$ aph $\left(3^{\prime \prime}\right)^{c}+a n t$ $\left(3^{\prime \prime}\right)^{b}+a p h(6)-1 d^{d}$ were strongly correlated with the collected samples from sites viz: finish water from Ife, tap water from Owena-Ijesha, raw water from Ede and tap water from Owena-oundo.

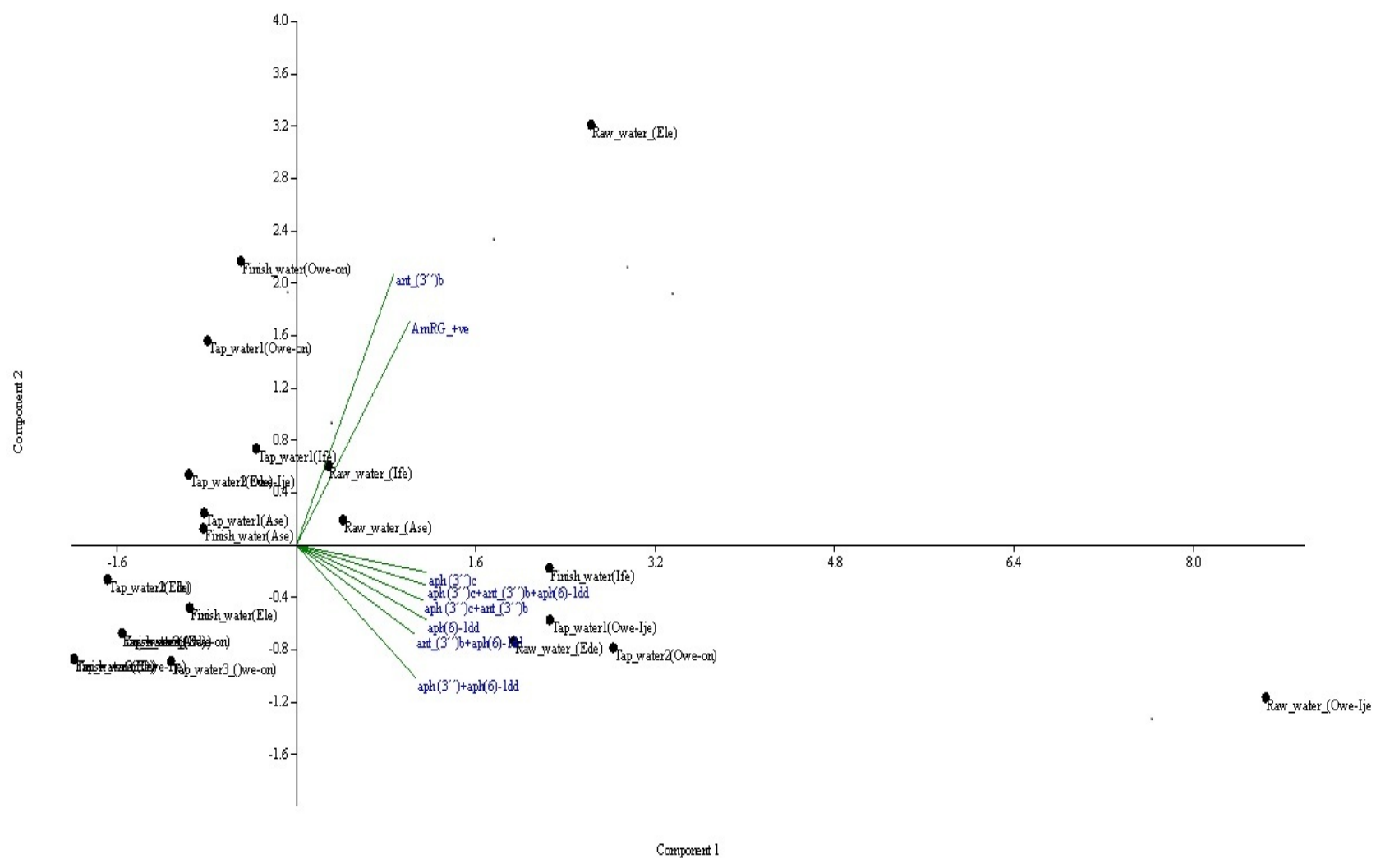

Figure 2: Biplot showing correlation between samples location and amplified genes using principal component analysis

DOI: http://dx.doi.org/10.4314/ejhs.v29i2.4 
Table 2: Summary of prevalence and total number of aminoglycoside-resistant bacteria species and genotypes

\begin{tabular}{|c|c|c|c|c|c|}
\hline Genus & $\begin{array}{l}\text { No of all } \\
\text { isolated } \\
\text { MDR }\end{array}$ & $\begin{array}{l}\text { No } \\
\text { (percentages) } \\
\text { of MDR testing } \\
\text { positive for } \\
\text { AmRG } \\
\end{array}$ & $\begin{array}{l}\text { Sources AmRG } \\
\text { isolates }\end{array}$ & AmR genotypes & $\begin{array}{l}\text { No of } \\
\text { Genus } \\
\text { positive } \\
\text { for } \\
\text { AmRG } \\
\end{array}$ \\
\hline Acinetobacter & 6 & $2(2.90)$ & EDM1 & $\begin{array}{l}\text { aph }\left(3^{\prime \prime}\right)^{c} \\
\text { ant }\left(3^{\prime \prime}\right)^{b}\end{array}$ & $\begin{array}{l}1 \\
1\end{array}$ \\
\hline Aeromonas & 5 & $3(4.35)$ & IFRW, ERW & $\begin{array}{l}\operatorname{aph}\left(3^{\prime \prime}\right)^{c} \\
\operatorname{ant}\left(3^{\prime \prime}\right)^{b} \\
\operatorname{aph}(6)-1 d^{d} \\
\operatorname{aph}\left(3^{\prime \prime}\right)^{c}+\operatorname{ant}\left(3^{\prime \prime}\right)^{b}+ \\
\operatorname{aph}(6)-1 d^{d}\end{array}$ & $\begin{array}{l}1 \\
3 \\
1 \\
1\end{array}$ \\
\hline Alcaligenes & 20 & $11(15.92)$ & $\begin{array}{l}\text { IFFW, ERW, } \\
\text { EM1,OWODFW, } \\
\text { OWODM2, } \\
\text { OWIRW, } \\
\text { OWIM1, OWIM2 }\end{array}$ & $\begin{array}{l}\operatorname{aph}\left(3^{\prime \prime}\right)^{c} \\
\operatorname{ant}\left(3^{\prime \prime}\right)^{b} \\
\operatorname{aph}(6)-1 d^{d} \\
\operatorname{aph}\left(3^{\prime \prime}\right)^{c}+\operatorname{ant}\left(3^{\prime \prime}\right)^{b}+ \\
\operatorname{aph}(6)-1 d^{d}\end{array}$ & $\begin{array}{l}3 \\
10 \\
2 \\
2\end{array}$ \\
\hline Bacillus & 45 & $6(8.70)$ & $\begin{array}{l}\text { IFW, IFM1, } \\
\text { EDRW, EDM1, } \\
\text { OWODFW, } \\
\text { OWODM1, } \\
\text { OWIRW }\end{array}$ & $\begin{array}{l}\operatorname{aph}\left(3^{\prime \prime}\right)^{c} \\
\operatorname{ant}\left(3^{\prime \prime}\right)^{b} \\
\operatorname{aph}(6)-1 d^{d} \\
\operatorname{aph}\left(3^{\prime \prime}\right)^{c}+\operatorname{ant}\left(3^{\prime \prime}\right)^{b} \\
\operatorname{aph}\left(3^{\prime \prime}\right)^{c}+\operatorname{ant}\left(3^{\prime \prime}\right)^{b}+ \\
\operatorname{aph}(6)-1 d^{d}\end{array}$ & $\begin{array}{l}2 \\
6 \\
1 \\
1 \\
1\end{array}$ \\
\hline Bordetella & 1 & $1(1.45)$ & EDRW & $\begin{array}{l}\operatorname{aph}\left(3^{\prime \prime}\right)^{c} \\
\operatorname{aph}(6)-1 d^{d} \\
\operatorname{aph}\left(3^{\prime \prime}\right)^{c}+\operatorname{aph}(6)-1 d^{d}\end{array}$ & $\begin{array}{l}1 \\
1 \\
1\end{array}$ \\
\hline Brevundimonas & 2 & $1(1.45)$ & IFFW & $\begin{array}{l}\operatorname{aph}\left(3^{\prime \prime}\right)^{c} \\
\operatorname{ant}\left(3^{\prime \prime}\right)^{b} \\
\operatorname{aph}(6)-1 d^{d} \\
\operatorname{aph}\left(3^{\prime \prime}\right)^{c}+\operatorname{ant}\left(3^{\prime \prime}\right)^{b}+ \\
\operatorname{aph}(6)-1 d^{d}\end{array}$ & $\begin{array}{l}1 \\
1 \\
1 \\
1 \\
1\end{array}$ \\
\hline Chromobacterium & 5 & $3(4.35)$ & $\begin{array}{l}\text { IFM1, EDRW, } \\
\text { AM1 }\end{array}$ & $\begin{array}{l}\operatorname{aph}\left(3^{\prime \prime}\right)^{c} \\
\operatorname{ant}\left(3^{\prime \prime}\right)^{b} \\
\operatorname{aph}\left(3^{\prime \prime}\right)^{c}+\operatorname{ant}\left(3^{\prime \prime}\right)^{b}\end{array}$ & $\begin{array}{l}1 \\
3 \\
1\end{array}$ \\
\hline Klebsiella & 14 & $8(11.59)$ & $\begin{array}{l}\text { AFW, ERW, } \\
\text { OWODFW, } \\
\text { OWIRW, OWIM1 }\end{array}$ & $\begin{array}{l}\text { aph }\left(3^{\prime \prime}\right)^{c} \\
\operatorname{ant}\left(3^{\prime \prime}\right)^{b}\end{array}$ & $\begin{array}{l}1 \\
7\end{array}$ \\
\hline Leucobacter & 2 & $2(2.90)$ & $\begin{array}{l}\text { ARW, } \\
\text { OWODRW }\end{array}$ & $\operatorname{aph}\left(3^{\prime \prime}\right)^{c}$ & 2 \\
\hline Morganella & 7 & $2(2.90)$ & EDFW, ERW & $\begin{array}{l}\operatorname{aph}\left(3^{\prime \prime}\right)^{c} \\
\operatorname{ant}\left(3^{\prime \prime}\right)^{b}\end{array}$ & $\begin{array}{l}1 \\
1\end{array}$ \\
\hline $\begin{array}{l}\text { Pantoae } \\
\text { Proteus }\end{array}$ & $\begin{array}{l}1 \\
22\end{array}$ & $\begin{array}{l}1(1.45) \\
16(23.19)\end{array}$ & $\begin{array}{l}\text { OWODM1 } \\
\text { EDRW, ARW, } \\
\text { AFW, AM2, } \\
\text { ERW, EFW, } \\
\text { OWODFW, } \\
\text { OWODM1, } \\
\text { OWODM3, } \\
\text { OWIRW,OWIM2, } \\
\text { IFFW }\end{array}$ & $\begin{array}{l}\operatorname{ant}\left(3^{\prime \prime}\right)^{b} \\
\operatorname{aph}\left(3^{\prime \prime}\right)^{c} \\
\text { ant }\left(3^{\prime \prime}\right)^{b} \\
\operatorname{aph}(6)-1 d^{d} \\
\operatorname{aph}\left(3^{\prime \prime}\right)^{c}+\operatorname{ant}\left(3^{\prime \prime}\right)^{b} \\
\operatorname{aph}\left(3^{\prime \prime}\right)^{c}+\operatorname{ant}\left(3^{\prime \prime}\right)^{b}+ \\
\operatorname{aph}(6)-1 d^{d}\end{array}$ & $\begin{array}{l}1 \\
11 \\
7 \\
4 \\
1 \\
2\end{array}$ \\
\hline Providencia & 5 & $3(4.35)$ & $\begin{array}{l}\text { IFRW, } \\
\text { OWODM2, }\end{array}$ & $\begin{array}{l}\text { aph }\left(3^{\prime \prime}\right)^{c} \\
\text { ant }\left(3^{\prime \prime}\right)^{b} \\
\operatorname{aph}(6)-1 d^{d}\end{array}$ & $\begin{array}{l}2 \\
1 \\
1\end{array}$ \\
\hline
\end{tabular}

DOI: http://dx.doi.org/10.4314/ejhs.v29i2.4 
Table 2. continued....

\begin{tabular}{|c|c|c|c|c|c|}
\hline Psychrobacter & 2 & $2(2.90)$ & EDM2, & $\operatorname{aph}\left(3^{\prime \prime}\right)^{c}$ & 1 \\
\hline & & & OWODM3 & ant $\left(3^{\prime \prime}\right)^{b}$ & 1 \\
\hline Serratia & 2 & $1(1.45)$ & OWIRW & $\operatorname{aph}\left(3^{\prime \prime}\right)^{c}$ & 1 \\
\hline Uncultured & 7 & $3(4.35)$ & IFM1, ARW, & $\operatorname{aph}\left(3^{\prime \prime}\right)^{c}$ & 2 \\
\hline bacteria Clone & & & AM1 & ant $\left(3^{\prime \prime}\right)^{b}$ & 3 \\
\hline & & & & $\operatorname{aph}(6)-1 d^{d}$ & 1 \\
\hline & & & & $\operatorname{aph}\left(3^{\prime \prime}\right)^{c}+\operatorname{ant}\left(3^{\prime \prime}\right)^{b}$ & 2 \\
\hline & & & & $\begin{array}{l}\operatorname{aph}\left(3^{\prime \prime}\right)^{c}+\operatorname{ant}\left(3^{\prime \prime}\right)^{b}+ \\
\operatorname{aph}(6)-1 d^{d}\end{array}$ & 1 \\
\hline
\end{tabular}

Codes: IRW $=$ Ife raw water, IFFW $=$ Ife treated water, IFM1 and IFM2 = Ife municipal tap 1 and 2, EDRW = Ede raw water, $\mathrm{EDFW}=$ Ede treated water, EDM1 and EDM2 = Ede municipal tap 1 and 2, ARW = Asejire raw water, $\mathrm{AFW}=$ Asejire treated water, AM1 and AM2 = Asejire municipal tap 1 and 2, ERW = Eleyele raw water, EFW = Eleyele treated water, EM1 and EM2 = Eleyele municipal 1 and 2, OWODRW = Owena Ondo raw water, OWODFW = Owena Ondo treated water, OWODM1 and OWODM2 = Owena-ondo municipal tap 1 and 2, OWIRW = OwenaIdanre raw water, OWIFW= Owena-Idanre treated water, OWIM1 and OWIM2 = Owena-Idanre municipal tap 1 and 2 Note: Bacteria was identified to the genus level by $16 \mathrm{~S}$ rDNA partial Sequence

$\mathrm{AmRG}=$ Aminoglycoside resistance gene

However, bacteria such as Aquitalae, Camamonas, Enterobacteria, Lysinibacillus, Myroids, Pseudochrobactrum, Sphingobacterium, Staphylococcus, Stenotrophomonas, Ralstonia and Trabusiella were genotypes but none showed the presence of any of the AME amplified in this study (Data not shown). The plasmid profiling of these MDR bacteria showed that they consist of plasmid size of between $28 \mathrm{~kb}$ and $130 \mathrm{~kb}$. The majority of the bacteria carried one plasmid while few like Proteus mirabilis with strain ID 18B2 and Proteus vulgaris with strain ID 46 from Dam 3 and Dam 4 respectively both carried two plasmid each (Table 3).

Table 3: Plasmid carrying bacteria isolated from selected water samples from southwestern Nigeria

\begin{tabular}{|c|c|c|c|}
\hline Source & Bacteria/Strain ID & Resistance Phenotypes & No of Plasmid and Size \\
\hline DAM 1 IRW & Escherichia coli (319A) & T,S, C, N, SXT, SU & $1(95 \mathrm{~kb})$ \\
\hline DAM 1 IFW & Alcaligenes sp (87A) & $\mathrm{T}, \mathrm{S}, \mathrm{AM}, \mathrm{SXT}, \mathrm{SU}$ & $1(28 \mathrm{~kb})$ \\
\hline DAM 1 IFW & Proteus mirabilis (122A) & $\mathrm{FF}, \mathrm{T}, \mathrm{S}, \mathrm{G}, \mathrm{K}, \mathrm{C}, \mathrm{AMC}, \mathrm{AM}, \mathrm{SU}, \mathrm{SXT}$ & $1(28 \mathrm{~kb})$ \\
\hline DAM 2 EDRW & Chromobacterium violaceum (382) & $\mathrm{S}, \mathrm{G}, \mathrm{CEF}, \mathrm{AM}, \mathrm{SXT}, \mathrm{AMC}, \mathrm{SU}$ & $1(95 \mathrm{~kb})$ \\
\hline DAM 2 EDFW & Morganella sp $(\mathrm{U})$ & $\mathrm{T}, \mathrm{S}, \mathrm{AM}, \mathrm{SXT}, \mathrm{SU}$ & $1(28 \mathrm{~kb})$ \\
\hline DAM 2 EDFW & Alcaligenes faecalis (28A) & $\mathrm{T}, \mathrm{S}, \mathrm{G}, \mathrm{K}, \mathrm{N}, \mathrm{CEF}, \mathrm{AM}, \mathrm{SXT}, \mathrm{SU}$ & $1(28 \mathrm{~kb})$ \\
\hline DAM 2 EDM1 & Klebsiella pneumoniae (378) & S, CEF, AM, SXT, AMC, SU & $1(95)$ \\
\hline DAM 2 EDM2 & Bacillus sp. (110) & SU, AM, SXT, LIN & $1(120 \mathrm{~kb})$ \\
\hline DAM 3 ARW & Proteus mirabilis (18B2) & $\mathrm{T}, \mathrm{S}, \mathrm{N}, \mathrm{SXT}, \mathrm{SU}$ & $2(130 \mathrm{~kb}$ and $38 \mathrm{~kb})$ \\
\hline DAM 4 ERW & Proteus vulgaris (33B) & $\mathrm{T}, \mathrm{C}, \mathrm{CEF}, \mathrm{AM}$ & $2(120 \mathrm{~kb}$ and $55 \mathrm{~kb})$ \\
\hline DAM 4 EFW & Proteus vulgaris (46) & FF, T, S, G, K, C, AM, SXT, N, AMC, SU & $1(55 \mathrm{~kb})$ \\
\hline DAM 5 OWODFW & Alcaligenes faecalis (197) & $\mathrm{T}, \mathrm{S}, \mathrm{K}, \mathrm{CEF}, \mathrm{AM}, \mathrm{SXT}, \mathrm{SU}$ & $1(55 \mathrm{~kb})$ \\
\hline DAM 5 OWODFW & Alcaligenes sp. (198) & $\mathrm{T}, \mathrm{S}, \mathrm{K}, \mathrm{AM}, \mathrm{SXT}, \mathrm{SU}$ & $1(28 \mathrm{~kb})$ \\
\hline DAM 5 OWODFW & Morganella morganii (199) & S, CEF, AM, AMC, SU & $1(55 \mathrm{~kb})$ \\
\hline DAM 5 OWODFW & Bacillus sp (202B) & SU, AM, T, SXT, GEN & $1(95 \mathrm{~kb})$ \\
\hline DAM 5 OWODM1 & Morganella morganii (215A) & $\mathrm{T}, \mathrm{S}, \mathrm{CEF}, \mathrm{AM}, \mathrm{SXT}, \mathrm{AMC}, \mathrm{SU}$ & $2(120 \mathrm{~kb}$ and $28 \mathrm{~kb})$ \\
\hline DAM 5 OWODM2 & Escherichia coli (210A) & $\mathrm{T}, \mathrm{AM}, \mathrm{SXT}, \mathrm{AMC}, \mathrm{SU}$ & $1(55 \mathrm{~kb})$ \\
\hline DAM 5 OWODM2 & Bacillus cereus (245B) & SU, AM, SXT, LIN & $1(95 \mathrm{~kb})$ \\
\hline DAM 5 OWODM2 & Alcaligens feacalis (253A) & $\mathrm{T}, \mathrm{S}, \mathrm{G}, \mathrm{K}, \mathrm{C}, \mathrm{AM}, \mathrm{SXT}, \mathrm{SU}$ & $1(120 \mathrm{~kb})$ \\
\hline DAM 5 OWODM2 & Escherichia coli (210B) & $\mathrm{T}, \mathrm{AM}, \mathrm{AMC}, \mathrm{SU}$ & $1(95 \mathrm{~kb})$ \\
\hline DAM 6 OWIRW & Alcaligenes faecalis (173B) & T, S, CEF, SXT, AMC, SU & $1(55 \mathrm{~kb})$ \\
\hline
\end{tabular}

DOI: http://dx.doi.org/10.4314/ejhs.v29i2.4 
Table 3. Continued...

\begin{tabular}{llll} 
DAM 6 OWIM1 & Alcaligenes $s p(250 \mathrm{~B} 2)$ & T, S, K, N, CEF, SU & $2(120 \mathrm{~kb}$ and $22 \mathrm{~kb})$ \\
DAM 6 OWIM2 & Alcaligenes $s p(238 \mathrm{~B})$ & T, S, G, K, N, CEF, AM, SU & $1(55 \mathrm{~kb})$ \\
DAM 6 OWIM2 & Alcaligenes faecalis $(239)$ & T, S, K, CEF, AM, SXT, SU & $1(95 \mathrm{~kb})$ \\
\hline
\end{tabular}

Codes: IRW $=$ Ife raw water, IFFW $=$ Ife treated water, IFM1 and IFM2 $=$ Ife municipal tap 1 and 2, EDRW $=$ Ede raw water, $\mathrm{EDFW}=$ Ede treated water, EDM1 and $\mathrm{EDM} 2=$ Ede municipal tap 1 and 2, ARW $=$ Asejire raw water, AFW $=\mathrm{Asejire}$ treated water, $\mathrm{AM} 1$ and $\mathrm{AM} 2=$ Asejire municipal tap 1 and 2, ERW = Eleyele raw water, EFW = Eleyele treated water, EM1 and EM2 = Eleyele municipal 1 and 2, OWODRW = Owena Ondo raw water, OWODFW = Owena Ondo treated water, OWODM1 and OWODM2 = Owena-ondo municipal tap 1 and 2, OWIRW $=$ Owena-Idanre raw water, OWIFW= Owena-Idanre treated water, OWIM1 and OWIM2 = Owena-Idanre municipal tap 1 and 2

Gram negative Antibiotics: Ampicillin (AM);Ceftiofur (CEF); Chloramphenicol and Florfenicol (FF); Kanamycin (K), Streptomycin (S) and Gentamycin (GEN); Tetracycline (T); Nalidixic Acid (N); Sulfamethoxazole (SU); Sufamethoxazole/ Trimethoprim (SXT); Amoxicillin/Clavulanic $\quad$ Acid $\quad$ (AMC) Gram positive Antibiotics: Sufamethoxazole (SU); Ampicillin (AM); Tetracycline (T); Gentamycin (GEN); Erythromycin; Riframprim (RIF);Lincomycin (LIN); Ciprofloxacin (CIP), Sulfamethoxazole/Trimethoprin (SXT)

\section{DISCUSSION}

In recent years, increasing occurrence of aminoglycoside resistant strains has posed a major threat not only because of their ability to cause serious infections but also because of their increasing resistance to several antimicrobial agents (27). The majority of epidemiological studies have focused on the spread of resistance in human pathogens while few studies have documented the occurrence of antibiotic resistance genes such as AMEs among environment bacteria. In this study, we detected aph $\left(3^{\prime \prime}\right)^{c}$, ant $\left(3^{\prime \prime}\right)^{b}$ and aph(6)$1 d^{d}$ among a wide range of environmentally significant bacteria from treated and untreated water from dams in Nigerian water distribution systems. Our previous work on these bacteria reported tetracycline resistance gene (25), beta-lactam resistance gene (28) and integron and gene cassette harboring other antibiotic resistance (29) genes among these bacteria. These genes could be circulating among humans and animals who depend on these water sources as well as in the environments and among the aquatic animals in these environments. The occurrence of AMEs among non-clinical bacteria from this study is similar to the results of Heuer et al. (30), who reported six clusters of genes such (aac(3)-I, $\operatorname{aac}(3)-I I / V I, \operatorname{aac}(3)-I I I / I V, \operatorname{aac}(6 P)-I I / I b$, ant (2Q)-I, $\operatorname{aph}(2 Q)-I)$ encoding gentamicin resistance gene among Enterobacteriaceae, Pseudomonas and Acinetobacter from soil, rhizospheres, piggery manure, feaces from cattle, laying and broiler chicken, municipal and hospital sewage water and coaster water.
$51.7 \%)$, ant (2) (17.4 to 20.2\%) and aph (3) (5.6 to $10.1 \%$ ) among a total of 255 Gram-negative clinical isolates recovered from clinical specimens that included Acinetobacter sp (9\%), Escherichia coli (34.9\%), Pseudomonas sp (29\% and Klebsiella sp (27\%). The most prevalent AMEs gene detected in their study was aac (6) which was contrary to our observation in this study where ant $\left(3^{\prime \prime}\right)^{b}$ was the most prevalent gene detected. High occurrence of this gene was found among Alcaligenes sp (10/20) and Klebsiella sp (7/14). This is related to the work of Manu and Anurag. (2014) who reported the presence of ant (2) among 13 Klebsiella sp from clinical source. Futhermore, Alcaligenes was not isolated in their studies. Moreover, we did not find the presence of these genes in Alcaligenes in any literature; our study could be the first report of such occurrence. van Oveerbeek et al., (31) reported the gene among Proteus spp from European habitat which include bulk and rhizosphere soils, manure from farm animals, activated sludge from waste water treatment plants and seawater. In this study, aph $\left(3^{\prime \prime}\right)^{c}$ was the second most detected gene among the 3 AMEs amplified while it was mostly (11/22) detected among Proteus spp. Seven and four Proteus spp also showed the presence of ant $\left(3^{\prime \prime}\right)^{b}$ and $a p h(6)-1 d^{d,}$ respectively. Occurrence of AME in Proteus is similar to the studies of Wieczorek et al. (32) who also reported aac(6')$1 b$ among Proteus from clinical samples from Poland.

Most of the bacteria observed in this study which seem to be carriers of these AMEs are opportunistic bacteria from aquatic environment. In

DOI: http://dx.doi.org/10.4314/ejhs.v29i2.4 
Nigeria, Igbinosa and Oviasogie (33) also reported the presence of AME such as aacA4, aadA2, aadB, $a a c C 4$ and $a a c A 6$ '- $1 b$ associated with class 1 integron among environmental Stenotrophomonas maltophilia. Meanwhile, from our previous studies on these same group of environmental isolates, where the integrase gene was genotype. We observed the presence of aadA2, aadA1 and aadB associated with some of their class 1 integrons while sat 2 was found associated with the class 2 integron of some of the isolated Proteus spp. Occurrence of these genes on mobile genetic element such as integrons showed that this gene could be transferred to other bacteria. Hence, there is a need for proper surveillance by public health workers.

Co-habitation of one or more AME genes in a single bacterium observed in many of these bacteria from this study is consistent with other previous studies in $P$. aeruginosa (34-36). Aeromonas, Alcaligenes, Brevundimonas, Proteus and an uncultured bacteria clone from this study showed the co-occurrence of aph $\left(3^{\prime \prime}\right)^{c}$, ant $\left(3^{\prime \prime}\right)^{b}$ and aph (6)- $1 d^{d}$ in a single specie.

Plasmids carried by bacteria reported in this study were observed to be bigger in size than those reported by Aja et al. (37), Shafiani and Malik. (38) and Wang et al. (39). However, it is well known that plasmid is one of the most important mediators facilitating the fast spreading of antibiotic resistance in bacteria (40). Therefore, their occurrence among these bacteria from these water distribution systems suggest the occurrence of some of these genes on them, hence enhancing their shuttling to bacteria present in the Gastrointestinal tract (GIT) of the consumers. Thereby, causing greater havoc of antibiotic-resistant bacteria to the consumers of these drinking water.

In conclusion, this study observed high occurrence of aminoglycoside modifying genes such as ant $(3 ")^{c}(27.62 \%)$ and aph (3") ${ }^{c}(18.23 \%)$ among MDR bacteria from southwestern Nigeria drinking water distribution systems. The most worrisome part is the detection of these genes among bacteria from drinking taps and the occurrence of plasmid of different sizes among these bacteria. This calls for urgent attention as monitoring of aminoglycoside modifying genes is necessary considering their co-selection and easy dissemination among MDR bacteria that could be located in the consumers of the tap water. Hence, difficulty in treating human and animal infection among water consumers. A call for a functional antimicrobial resistance surveillance program among environmental clinical bacteria in Nigeria is very important.

\section{ACKNOWLEDGEMENTS}

We acknowledge Dr. Call R. Douglas who helped with the partial support from the Department of Veterinary Microbiology and Pathology and the Paul G. Allen School for Global Animal Health at, Washington State University, Pullman, USA. Lisa Orfe who provided invaluable technical support. Federal University Dutsin-Ma, Dutsin-Ma, Katsina State, Nigeria is also appreciated for giving the first author one year study fellowship to complete this research work during his $\mathrm{PhD}$. Dr. Eluwole Akinola and Dr. Matouke Matouke Moise, who drew the GIS map of the sampled dams and the statistical analysis respectively, are also immensely appreciated.

\section{REFERENCES}

1. Vakulenko SB, Mobashery S. Versatility of aminoglycosides and prospects for their future. Clin Microbiol Rev. 2003; 16: 430-450.

2. Shakil S, Khan R, Zarrilli R, Khan AU. Aminoglycosides versus bacteria-a description of the action, resistance mechanism, and nosocomial battleground. J. Biomed. Sci._2008; 15: 5-14

3. Gad GF, Mohamed HA, Ashour HM. Aminoglycoside resistance rates, phenotypes, and mechanisms of Gramnegative bacteria from infected patients in upper Egypt. PLOS ONE. 2011; 6: e17224.

4. Suthar S. Contaminated drinking water and rural health perspectives in Rajasthan, India: an overview of recent case studies," Environmental Monitoring and Assessment. 2011; 173: 837-849.

5. World Health Organization (WHO), Emerging Issues in Water and Infectious

DOI: http://dx.doi.org/10.4314/ejhs.v29i2.4 
Disease, World Health Organization (WHO), Geneva, Switzerland. 2003

6. Xi C, Zhang Y, Marrs CF, Ye W, Simon C. Prevalence of Antibiotic Resistance in Drinking Water Treatment and Distribution Systems. Appl Environ Microbiol. 2009. 75:5714-5718.

7. De la Cruz F, Davies J. Horizontal gene transfer and the origin of species: lessons from bacteria. Trends Microbiol. 2000; 3:128- 133

8. Shaw KJ, Rather PN, Hare RS, Miller GH. Molecular genetics of aminoglycoside resistance genes and familial relationships of the aminoglycoside modifying enzymes. Microbiol. Rev. 1993; 57: 138-163.

9. Hall RM. Mobile gene cassettes and integrons: moving antibiotic resistance genes in Gram-negative bacteria. In: Antibiotic Resistance: Origins, Evolution, Selection and Spread (Chadwick, D.J. and Goode, J., Eds.). 1997; pp. 192-202. John Wiley and Sons, Chichester

10. Wang Y, Ha U, Zeng L, Jin S. Regulation of membrane permeability by a Twocomponent regulatory system in Pseudomonas aeruginosa. Antimicrob. Agents Chemother. 2003; 47: 95-101.

11. Davies J and Wright G. Bacterial Resistance to Aminoglycoside Antibiotics. Trends in Microbiol. 1997; 5: 234-39.

12. Doi Y and Arakawa Y. 16S Ribosomal RNA Methylation: Emerging Resistance Mechanism against Aminoglycosides. Clin. Infect. Dis. 2007; 45: 88-94.

13. Poole, K., Efflux-mediated multi resistance in Gram-negative bacteria. Clin. Microbiol. Infect. 2004; 10: 12-26.

14. Mao W, Warren MS, Lee A, Mistry A, Lomovskaya O. MexXY-OprM efflux pump is required for antagonism of aminoglycosides by divalent cations in Pseudomonas aeruginosa Antimicrob. Agents Chemother. 2001; 45: 2001-2007.

15. Shahid M, Malik A. Resistance due to aminoglycoside modifying enzymes in Pseudomonas aeruginosa isolates from burns patients. Indian J. Med. Res. 2005; 122: 324-32.

16. Ubukata K, Yamashita N, Gotoh A, Konno M. Purification and characterization of aminoglycosidemodifying enzymes from Staphylococcus aureus and Staphylococcus epidermidis. Antimicrob Agents Chemother. 1984; 25 : 754-9.

17. Matsumara M, Katakura $T$, Imanaka $T$, Aiba S. Enzymatic and nucleotide sequence studies of a kanamycininactivating enzyme encoded by a plasmid from thermophilic bacilli in comparison with that encoded by plasmid pUB110. J. Bacteriol. 1984; 160: 413-20

18. Paulsen IT, Firth N, Skurray RA. Resistance to antimicrobial agents other than beta- lactams. In The Staphylococci in human disease, Eds., Crossley K.B. and Archer GL., Churchill Livingstone, New York Publishers; 1997 pp: 175-212.

19. Odumosu BT, Adeniyi BA, Chandra R. Occurrence of aminoglycoside-modifying enzymes genes (aac $\left(6^{\prime}\right)$-I and ant $\left.\left(2^{\prime \prime}\right)-\mathrm{I}\right)$ in clinical isolates of Pseudomonas aeruginosa from Southwest Nigeria. Afri Health Sci. 2015; 15(4):1277-81. http://dx.doi.org/10.4314/ahs.v15i4.29

20. Schmieder R, Edwards, R. Insights into antibiotic resistance through metagenomic approaches. Future Microbiol. 2012; 7: 73-89.

21. Adesoji AT, Ogunjobi AA. Physicochemical Properties and Occurrence of Antibiotic-Resistant Bacteria in Ife and Ede Water Distribution Systems of Southwestern Nigeria. World Applied Sci J. 2013a; 27:1098-110.

22. Adesoji AT, Ogunjobi AA. Occurrence of Multidrug-Resistant Bacteria in Selected Water Distribution Systems in Oyo State, Nigeria. Global Veterinaria. 2013b; 11:214-24.

23. Adesoji AT, Ogunjobi AA, Olatoye IO. Drinking Water Distribution Systems of Dams in Ondo State, Nigeria as Reservoir

DOI: http://dx.doi.org/10.4314/ejhs.v29i2.4 
of Multi-Drug Resistant Bacteria. World Applied Sci J. 2014; 32:403-14.

24. Adesoji AT, Ogunjobi AA, Olatoye IO, Call DR. Prevalence of tetracycline resistance genes among multi-drug resistant bacteria from selected water distribution systems in southwestern Nigeria. Annals of Clinical Microbiology and Antimicrobials. 2015a; 14:35

25. Adesoji AT, Ogunjobi AA, Olatoye IO. Molecular characterization of selected multidrug resistant Pseudomonas from water distribution systems in southwestern Nigeria. Annals of Clinical Microbiology and Antimicrobials. 2015b; 14:39

26. Manu C, Anurag P. Resistance Patterns and Prevalence of the Aminoglycoside Modifying Enzymes in Clinical Isolates of Gram Negative Pathogens. Global Journal of Pharmacology. 2014; 8 (1): 73-79.

27. Adesoji AT, Ogunjobi AA. Detection of Extended Spectrum Beta-Lactamases Resistance Genes among Bacteria Isolated from Selected Drinking Water Distribution Channels in Southwestern Nigeria. BioMed Research International. 2016. Volume 2016, Article ID 7149295 , 9 pages. dx.doi.org/10.1155/2016/7149295

28. Adesoji AT, Ogunjobi AA, Olatoye IO. Characterization of Integrons and Sulfonamide Resistance Genes among Bacteria from Drinking Water Distribution Systems in Southwestern Nigeria. Chemotherapy. 2017. 62:34-42

29. Heuer H, Krogerrecklenfort E, Wellington EMH, Egan S, van Elsas JD, van Overbeek L, Collard JM, Guillaume G, Karagouni AD, Nikolakopoulou TL, Smalla K. Gentamicin resistance genes in environmental bacteria: prevalence and transfer. FEMS Microbiology Ecology. 2002; 42: 289-302

30. van Overbeek LS, Wellington EMH, Egan S, Smalla K, Heuer H, Collard J, Guillaume G,Karagouni AD, Nikolakopoulou TL, van Elsas JD.
Prevalence of streptomycin-resistance genes in bacterial populations in European habitats. FEMS Microbiology Ecology. 2002; 42: 277-288

31. Wieczorek P, Sacha P, Hauschild T, Ostas A, Klosowska W, Ratajczak J, Tryniszewska E. The aac(6) Ib gene in Proteus mirabilis strains resistant to aminoglycosides. Folia Histochem Cytobiol. 2008; 46(4): (531-533)

32. Igbinosa EO, Oviasogie FE. Multiple antibiotics resistant among environmental isolates of Stenotrophomonasmaltophilia. J. Appl. Sci. Environ. Manage. 2014. 18 (2): 255-261

33. Miller GH, Sabatelli FJ, Hare RS, Glupczynski Y, Mackey P, Shlaes D, Shimizu K, Shaw KJ The most frequent aminoglycoside resistance mechanismschanges with time and geographic area: a reflection of aminoglycoside usage patterns? Aminoglycoside Resistance Study Groups. Clin Infect Dis. 1997;24: 46-62.

34. Kim JY, Park YJ, Kwon HJ, Han K, Kang MW, Woo GJ. Occurrence and mechanisms of amikacin resistance and its association with beta-lactamases in Pseudomonasaeruginosa: a Korean nationwide study. $J$ Antimicrob Chemother. 2008;62: 479-483.

35. Vaziri F, Peerayeh SN, Nejad QB, Farhadian A. The prevalence of aminoglycoside-modifying enzyme genes (aac (6')-I, aac (6')-II, ant (2")-I, aph (3')- VI) in Pseudomonas aeruginosa. Clinics. 2011; 66: 1519-1522.

36. Aja, A. M., Gasca, A. G., Grobois, A. A., Mejia, C. B., Roque A. and Gil, B.G. 2002. Plasmid profiling and antibiotic resistance of Vibrio strains isolated from cultured penaeid shrimp. FEMS Microbiology Letters. 213: 7-12

37. Shafiani, S and Malik. 2003. Tolerance of pesticides and antibiotic resistance in bacteria isolated from wastewater irrigated soil. World Journal of Microbiology and Biotechnology. 19: 897-901 
38. Wang, Y., Leung, P. C., Qian, P. Y. and $\mathrm{Gu}$, J. D. 2006. Antibiotic resistance and plasmid profile of environmental isolates of vibro species from Mai Po Nature Researve, Hong Kong. Ecotoxicology. 15: 371-378.
39. Dale, J. W. and Park, S. 2004. Molecular Genetics of Bacteria. $4^{\text {th }}$ Edition., John Wiley and Sons Incoporated., Chichester, UK

DOI: http://dx.doi.org/10.4314/ejhs.v29i2.4 